University of Montana

ScholarWorks at University of Montana

6-2009

\title{
Global Population Dynamics and Hot Spots of Response to Climate Change
}

Eric Post

Jebediah Brodie

Mark Hebblewhite

University of Montana - Missoula, mark.hebblewhite@umontana.edu

Angela D. Anders

Julie A. K. Maier

See next page for additional authors

Follow this and additional works at: https://scholarworks.umt.edu/wildbio_pubs

Part of the Life Sciences Commons

Let us know how access to this document benefits you.

\section{Recommended Citation}

Post, Eric; Brodie, Jebediah; Hebblewhite, Mark; Anders, Angela D.; Maier, Julie A. K.; and Wilmers, Christopher C., "Global Population Dynamics and Hot Spots of Response to Climate Change" (2009). Wildlife Biology Faculty Publications. 2.

https://scholarworks.umt.edu/wildbio_pubs/2

This Article is brought to you for free and open access by the Wildlife Biology at ScholarWorks at University of Montana. It has been accepted for inclusion in Wildlife Biology Faculty Publications by an authorized administrator of ScholarWorks at University of Montana. For more information, please contact scholarworks@mso.umt.edu. 


\section{Authors}

Eric Post, Jebediah Brodie, Mark Hebblewhite, Angela D. Anders, Julie A. K. Maier, and Christopher C. Wilmers 


\title{
Global Population Dynamics and Hot Spots of Response to Climate Change
}

ERIC POST, JEDEDIAH BRODIE, MARK HEBBLEWHITE, ANGELA D. ANDERS, JULIE A. K. MAIER, AND CHRISTOPHER C. WILMERS

\begin{abstract}
Understanding how biotic and abiotic factors influence the abundance and distribution of organisms has become more important with the growing awareness of the ecological consequences of climate change. In this article, we outline an approach that complements bioclimatic envelope modeling in quantifying the effects of climate change at the species level. The global population dynamics approach, which relies on distribution-wide, datadriven analyses of dynamics, goes beyond quantifying biotic interactions in population dynamics to identify hot spots of response to climate change. Such hot spots highlight populations or locations within species' distributions that are particularly sensitive to climate change, and identification of them should focus conservation and management efforts. An important result of the analyses highlighted here is pronounced variation at the species level in the strength and direction of population responses to warming. Although this variation complicates species-level predictions of responses to climate change, the global population dynamics approach may improve our understanding of the complex implications of climate change for species persistence or extinction.
\end{abstract}

Keywords: global warming, population dynamics, environmental niche model, bioclimatic envelope modeling, extinction

defining pursuit in ecology is to understand the factors that determine and contribute to variation in the distribution and abundance of organisms. Classic ecological theory predicts, for example, that abundance may be limited primarily by abiotic factors at one extreme of a species' distribution, whereas at the other extreme, abundance may be limited primarily by biotic factors (MacArthur 1972). Understanding the role of abiotic factors (such as climate) in population dynamics has grown in urgency and importance in recent decades with increasing documentation of the effects of climate change on patterns of abundance, population dynamics, and species interactions (Fagan et al. 2001, Parmesan and Yohe 2003, Thomas et al. 2004). Furthermore, increasing climatic variation due to climate change may even contribute to greater extinction risk (Boyce et al. 2006) and lead to the reorganization of ecological communities (Araujo and Luoto 2007). Yet spatially comprehensive analyses focusing on single species have illustrated the difficulty inherent in making general assessments of species-level responses to climate change (Post 2005, Anders and Post 2006). As climate change threatens to reshuffle Earth's biota, the challenge to ecologists is to predict how the distribution and abundance of various species will change as a result of variation among populations of those species in the extent to which, and the direction in which, the populations respond to changes in climate. Meeting this challenge, we contend, requires distribution-wide analyses, wherein data on the dynamics of numerous populations throughout the distribution of a species of interest are analyzed retrospectively to quantify species' response to climate change.

The science of understanding the role of climate in specieslevel patterns of distribution and abundance, and of predicting species' responses to climate change, relies mainly on bioclimatic envelope modeling. Bioclimatic envelope models, which predict shifts in species' geographic ranges with concomitant shifts in underlying climatic conditions, have provided the broadest perspective so far on the issue of species' responses to past and future climate change (Pearson and Dawson 2003, Peterson AT et al. 2004, Hijmans and Graham 2006). But the approach embodied by bioclimatic envelope modeling considers only shifts in species' ranges, not their abundance, and assumes that species' distributions and 
range limits are determined primarily by interactions between a single organism and the abiotic environment (Peterson AT et al. 2002, Pearson and Dawson 2003). This approach may be applicable in single-species systems, but not where distribution or abundance can be influenced by species interactions or anthropogenic forces (Case and Taper 2000, Araujo and Luoto 2007, Heikkinen et al. 2007). In fact, species are often limited by biotic factors such as the presence or absence of other species and spatial variation in population regulation. For example, Case and Taper (2000) concluded that in temperate environments, the southern limit of species' distributions should be determined by the inability of organisms to adapt to changes in abiotic conditions, because interactions with competitors lead to low population density and, thus, reduced gene flow.

Recently, several studies have emphasized the importance of including species interactions in bioclimatic envelope models. Important examples of this include multispecies bioclimatic envelope models for boreal owls and butterflies in Scandanavia (Araujo and Luoto 2007, Heikkinen et al. 2007), which clearly show that inclusion of more complex species interactions improves ecologists' ability to predict the effects of climate change. Such analyses confirm that the factors influencing the population dynamics of any species most likely vary across the distribution of that species (Fagan et al. 2001, Parmesan and Yohe 2003, Thomas et al. 2004). New approaches that make use of knowledge of both the abiotic and biotic factors limiting species are needed to predict population and community response to climate change.

Bioclimatic envelope models (also known as environmental niche models) are best thought of as null models for species response to climate change, in which the set of species interactions influencing distribution and abundance remains fixed when a species shifts its range in accordance with changes in underlying abiotic conditions. Here, we suggest a new approach that complements and builds upon the insights gleaned from bioclimatic envelope models. Our approach is based on recent developments in the analysis of population dynamics at the scale of species' distributions. These advances highlight the utility of addressing distribution-wide population dynamics in a quantitative framework that is amenable to inclusion of the effects of species interactions (Forchhammer et al. 1998, Forcada et al. 2006, Grotan et al. 2008, Sandvik et al. 2008).

Building on traditional time-series analyses of singlespecies population dynamics, we outline an approach to identify local hot spots of species' responses to large-scale climatic variation and change, including warming. This approach moves beyond bioclimatic envelope modeling in that different populations will be allowed to respond differently to climate, and local areas where climate impacts may be felt more strongly can be identified. Yet the extent to which biotic factors influence spatial variation in population response to climate change is still mostly unknown in this first step, although statistical properties emerging from the time-series analyses demonstrated here can be used to infer-grossly- the roles of interacting species on patterns of response to climate change. In a second step, where population dynamics of multiple interacting species are known, we extend these time-series approaches to include dynamic interactions that provide an approach to identify the species interactions behind climate hot spots. The insights arising from use of these approaches will be of considerable value in informing a mechanistic understanding of patterns generated by bioclimatic envelope models. Hence, we do not advocate our approach as a replacement for bioclimatic envelope modeling, but rather as a complement to it.

\section{Spatial variation in population dynamics identifies hot spots of population response to global climate change}

In this section we review two recently published examples, and present a third example developed in this article, to reveal the utility of distribution-wide analyses for identifying largescale spatial variability in the magnitude of population response to climate change. Importantly, these examples highlight the tremendous variation across species' distributions in the response of local populations to climate change, and identify hot spots of population response to climatic warming. The existence of such hot spots, and the fact that they are readily identifiable through analyses such as those presented here, has obvious implications for the focusing of conservation and management efforts.

In the first example (Anders and Post 2006), long-term data from the Breeding Bird Survey were used to analyze the dynamics of yellow-billed cuckoos (Coccyzus americanus) in relation to intraspecific competition (i.e., density dependence) and climatic dynamics throughout the birds' breeding distribution in North America. This analysis revealed considerable spatial variation throughout the distribution of this species in the extent to which populations responded to both the North Atlantic Oscillation (NAO) and El Niño Southern Oscillation (ENSO) (figure 1). Most of this variation was explained by the magnitude of the correlation between those climate indices and local temperatures. In other words, wherever the signal of large-scale warming was clearest in local temperature trends, as indicated by the strongest correlations between local temperature and the NAO or ENSO indices, cuckoo populations showed the strongest response to large-scale warming. More revealing, however, was that across populations, the magnitude of population decline related directly to the strength of the population's response to warming.

This pattern suggests that continued warming will hasten the declines of cuckoo populations sensitive to climatic variation because of their elevated extinction risk in populations with increasing climate-induced demographic stochasticity (Boyce et al. 2006). The high spatial resolution of the data, which derive from closely spaced transects distributed throughout the cuckoo's range in North America (see Anders and Post 2006), also allows inferences regarding which populations of yellow-billed cuckoo are most likely at risk of declining with future warming. These appear to be located in 
the east Texas prairies, southern New England, Ohio hills, and dissected till plains ecoregions (see figure 1). But how does this example differ from projections of species response to climate change based on bioclimatic envelope models? Inferences about the demise or persistence of cuckoo populations might also have been drawn on the basis of patterns of population trends and their associations with abiotic conditions. The cuckoo analysis, however, also accounted statistically for the potentially confounding influences of intraspecific competition and spatial variation in density by including coefficients of direct density dependence and estimates of the mean size of each population in a subsequent meta-analysis of the magnitude of population response to climate change (see Anders and Post 2006); both of these influences might play a role in the susceptibility of populations to abiotic variation.

In the second example (Forchhammer et al. 2002, Post 2005, Post and Forchhammer 2006), analyses of caribou and wild reindeer (both Rangifer tarandus) dynamics throughout their present distribution revealed considerable spatial variation in population response to climate along latitudinal and longitudinal gradients that coincided spatially with gradients of influence of the NAO on local temperature variation throughout the Northern Hemisphere. These analyses also revealed a general trade-off across the distribution of this species between the strength of density-dependent selfregulation and abiotic limitation. The populations that were apparently most responsive or vulnerable to climatic warming were those at the northern limit of the species' circumpolar distribution. Also, time-series analyses of the data revealed the effects of density in previous years on current density, suggesting that large-scale spatial heterogeneity influences the importance of species interactions in local population dynamics (Forchhammer et al. 2002, Post 2005, Post and Forchhammer 2006); such lagged effects are often attributable to species interactions involving competitors or natural enemies (Framstad et al. 1997, Forchhammer and Asferg 2000, Bjørnstad et al.2001). Again, populations at the northern extent of the species' distribution were more likely to display simple dynamics with primarily abiotic limitation, whereas those at or near the southern limit of the distribution displayed more complex dynamics with direct and delayed density dependence; the latter finding suggests that species interactions, such as predation, act together with climate in the dynamics of populations at the southern limit of the distribution of this species. Such findings, based on analysis of individual populations distributed throughout a species' range, can provide insights into projections from bioclimatic envelope models that predict expansion at the northern limits of species' distributions but contractions at the southern limits in response to future warming.

We now expand upon previous analyses of the distributionwide data on caribou and reindeer populations using selfexciting threshold autoregressive (SETAR) analysis (Tong 1990, Ellis and Post 2004) with climate covariates, testing for nonlinearity in the dynamics of these populations and for improved fit over previous linear analyses. A brief back-
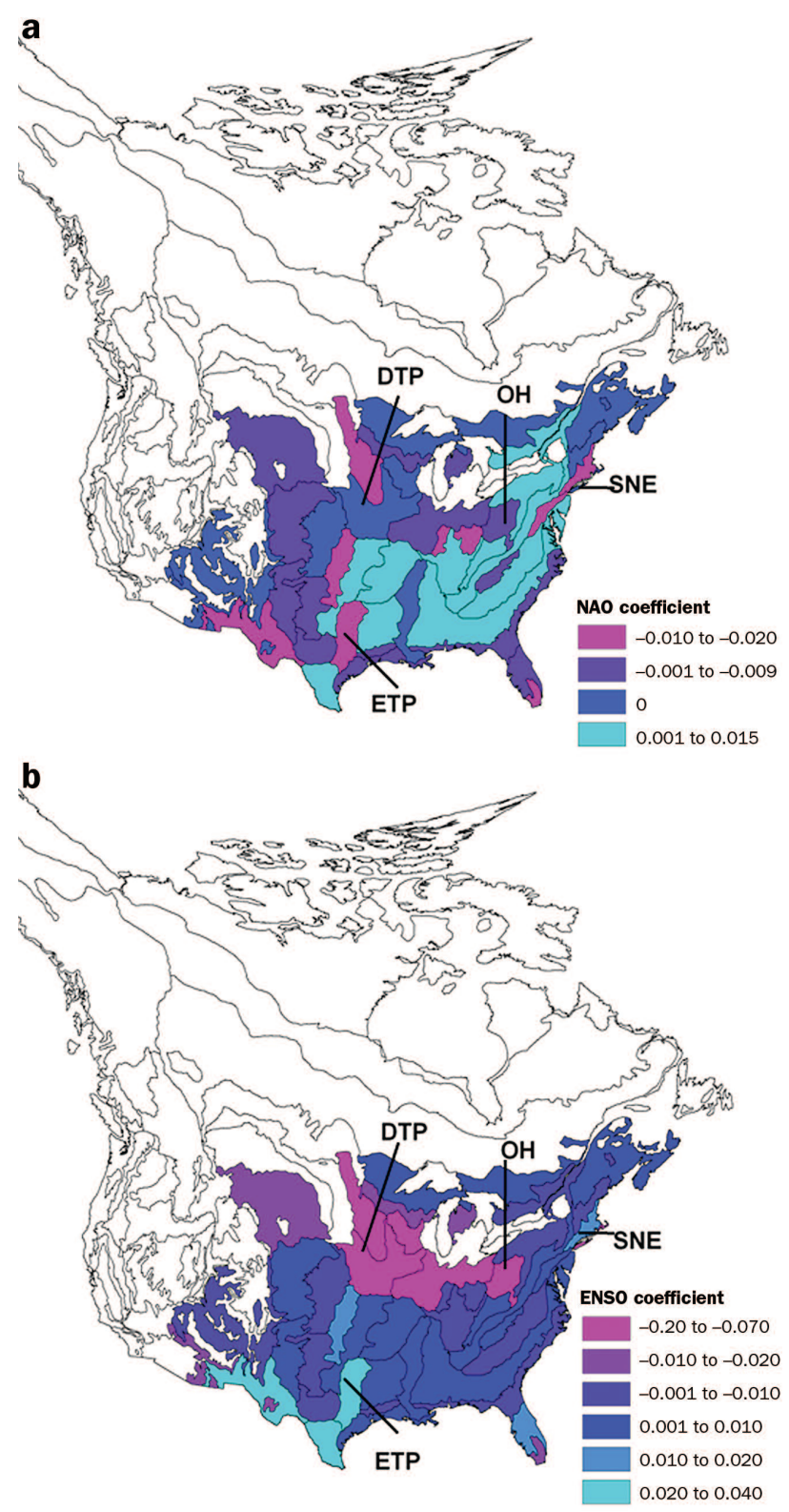

Figure 1. North American population dynamics analysis of yellow-billed cuckoos (Coccyzus americanus) showing the strength of one-year lagged relationships between the North Atlantic Oscillation (NAO) (a) and El Niño Southern Oscillation (ENSO) (b) and annual cuckoo population densities from 1966 to 2002. The magnitude of the NAO and ENSO coefficients are shown in color from red (negative, indicating a decline in abundance following an increase in the ENSO or NAO indices) to light blue (positive, indicating an increase in abundance following an increase in the ENSO or NAO indices). Ecoregion abbreviations: DTP, dissected till plains; ETP, east Texas prairies; $\mathrm{OH}$, Ohio hills; and SNE, southern New England.

ground on the form of the statistical models used in this retrospective time series analysis is warranted. As a starting point, we adhere to the simplifying assumption of nonlinear 
population growth approximated by the Gompertz equation (Bjørnstad et al. 1995, Gompertz 1825), in which the population growth rate changes log-linearly with abundance. As in previous applications of the Gompertz growth equation in the analysis of population dynamics of mammalian herbivores (Bjørnstad et al. 1995, Post and Stenseth 1999, Forchhammer et al. 2002), we began with a density-dependent model of population growth incorporating weather as a covariate:

$$
N_{t}=N_{t-1} \exp \left(\beta_{0}+\beta_{1} X_{t-1}+\Sigma \omega_{t-d} \operatorname{CLIM}_{t-d}+\sigma_{t}\right)
$$

In this equation, $N_{t}$ denotes abundance at time $t, X_{t}$ the natural $\log$ of abundance at time $t, \beta_{0}$ the intrinsic rate of population increase, $\beta_{1}$ the strength of direct density dependence, and CLIM some climate term such as the NAO or ENSO index, for which $\omega_{t-d}$ quantifies the strength of the climate effect on changes in abundance at lags up to $d$ years.

By taking the log of both sides of equation 1, we arrive at a first-order autoregressive (AR[1]) model of population dynamics that is amenable to statistical analysis (Bjørnstad et al. 1995):

$$
X_{t}=\beta_{0}+\left(1+\beta_{1}\right) X_{t-1}+\Sigma \omega_{t-d} \operatorname{CLIM}_{t-d}+\varepsilon_{t}
$$

Equation 2 can be extended to account for delayed density dependence by including the term $\beta_{2} X_{t-2}$ (Stenseth et al. 1996a, 1996b, Forchhammer et al. 1998, 2002). In the SETAR, nonlinear form of equation 2 , we relaxed the assumption that the coefficients of direct and delayed density dependence $\left(\beta_{1}\right.$ and $\left.\beta_{2}\right)$, or of the influence of climate on dynamics $\left(\omega_{t-d}\right)$, are constant regardless of whether the population is increasing or declining, and allowed the strength of density dependence and climatic influence to vary depending on the phase of population growth (i.e., increase or decline; Grenfell et al. 1998, Stenseth et al. 1998a, Forchhammer and Asferg 2000, Post et al. 2002, Ellis and Post 2004).

Following methods described elsewhere (Forchhammer et al. 1998, Stenseth et al. 1999), we analyzed each time series by determining the most parsimonious dimension or order (number of significant lags) of density dependence (either one or two) of each time series, thereby accounting for density dependence first, and then tested for significance of terms quantifying the contribution of Northern Hemisphere temperature anomalies (NHTA) at lags of one to three years; parsimony was determined on the basis of the lowest Akaike information criterion score, corrected for the number of covariates in the model (Sakamoto et al. 1986).

This analysis revealed not only spatial variation in the strength of Rangifer population responses to warming (NHTA) but also considerable spatial variation in the types of intrinsic dynamics they displayed (figure 2): approximately $15 \%$ of the populations displayed nonlinear responses to warming. Moreover, the populations most negatively affected by warming appear to be those in West Greenland, eastern Russia, and southern Alaska, whereas populations in other regions of the species' distribution are affected only weakly by warming, or are positively affected by it (figure 2). The importance of identifying nonlinearity in population dynamics lies in the fact that the susceptibility to climatic variation of populations with such dynamics can vary, depending on whether the population is in a low- or high-density regime, or on whether the population is increasing or declining (Grenfell et al. 1998, Bjørnstad and Grenfell 2001). Moreover, recent evidence from nonlinear modeling of population dynamics of Svalbard reindeer (Rangifer tarandus platyrhynchus) indicates that thresholds may simultaneously operate in both density and climatic conditions (Tyler et al. 2008), further complicating predictions of species-level response to climate change. Bioclimatic envelope models would not identify such nuances.

Using the same approach employed in analyzing the timeseries data on Rangifer in the example described above, we obtained and analyzed time-series data for the Cervus elaphus/ Cervus canadensis species complex (elk and red deer; hereafter Cervus) from across the global distribution of Cervus from the published literature (e.g., Jedrzejewska et al. 1997, CluttonBrock and Coulson 2002, Nikol'skii and Likhatskii 2002, Hebblewhite 2005, Vucetich et al. 2005). We analyzed these data using the same autoregressive linear and SETAR modeling approach described above, using time series for 34 Cervus populations from throughout the species' range in the Northern Hemisphere. This allowed us to quantify the influence of climate (here again, NHTA) on population dynamics after accounting statistically for contributions of direct- and delayed-density dependence. As in the Rangifer example, the Cervus population response to warming varied widely throughout the distribution of this species complex (figure 2). In the case of Cervus, however, there is strong spatial variation in the direction of response to warming even at relatively local scales, such as within the Rocky Mountains region, where dynamics of some populations responded positively and others negatively to warming (figure 2), perhaps because of the complicating influences of species interactions in some regions (sensu Wilmers et al. 2007).

Comparing Rangifer and Cervus in the strength of the correlation between the warming and population growth rate coefficients and the influence of NAO on local temperatures, we find further interesting and opposing patterns (figure 3). In areas where local temperatures are negatively related to the NAO, the population growth rate of Rangifer is negatively affected by large-scale warming $(r=0.44, p=0.01$, $n=38$ ). In contrast, Cervus populations show a negative response to warming in areas where there is a positive correlation between the NAO and temperature $(r=-0.39, p=0.02$, $n=34$ ) (figure 3 ). This comparative analysis suggests that climate change will influence these two species in opposition, potentially reflecting different mechanisms of climate impacts. For example, recent modeling shows that elk populations in Rocky Mountain National Park are expanding because of climatic amelioration (Wang et al. 2006), whereas Woodland caribou populations in North America are retreating northward, perhaps reflecting their adaptation to a colder 
bioclimatic envelope (Grayson and Delpech 2005). Despite such broad differences between these two species, much unexplained variation remains at the population level. We propose that this unexplained variance is most likely due to species interactions and differences between populations, as in the cuckoo example. Even simple knowledge of the presence or absence of key interacting species for each population-for example, whether wolves are present or absent (e.g., absent in Scotland, southern Greenland; present in Canada, Russia)—will enable subsequent analyses to examine species interactions in more detail.

A growing number of studies have employed similar ideas to regional or near distributionwide analyses of the effects of climate change on other species, including penguins, seabirds, and ungulate populations, but none has yet focused on population dynamics at the scale of species distributions. Nonetheless, these large-scale analyses are informative and encourage further large-scale analyses of species-level population dynamics. Using 33 time series for 13 different species of seabirds across the entire North Atlantic, for example, Sandvik and colleagues (2008) showed a strong latitudinal gradient in the connection between the NAO and breeding success. Northern populations were more likely than southern populations to suffer negative effects from severe winters, and the stronger the connection between local sea-surface temperature and the $\mathrm{NAO}$, the stronger the impact on breeding success. Taxonomic grouping and foraging strategies, however, strongly affected seabird responses to climate. The species-specific responses to climate strongly support the role of species interactions in mediating climate impacts on populations in North Atlantic seabirds.

In the southern Antarctic Ocean, Forcada and colleagues (2006) demonstrated similar variable responses of three species of penguins breeding at the same colony using timeseries analysis of population dynamics. Despite spatial co-occurrence, the three species of penguins responded dramatically differently to climate dynamics, leading Forcada and colleagues (2006) to conclude that species interactions were driving climate-population dynamics. Grotan and colleagues (2008) analyzed 26 populations of ibex (Capra ibex) populations in the Swiss Alps and found strong spatial variation in the effects of climate on local population responses, as did Wang and colleagues (2006) for six populations of ungulates in North America. Some populations responded to winter severity and others to spring precipitation, and populations showed weak to no spatial synchrony in response to climate. A common aspect of all global population dynamics analyses is the recurrent theme of pronounced variation in local populations' responses to climate, which suggests a strong role for species interactions in buffering responses to climate.

\section{Role of species interactions in buffering populations against climate change or in exacerbating populations' responses to climate change}

Analysis of the long-term observations of the abundance of moose and wolves on Isle Royale (Peterson RO et al. 1998, 


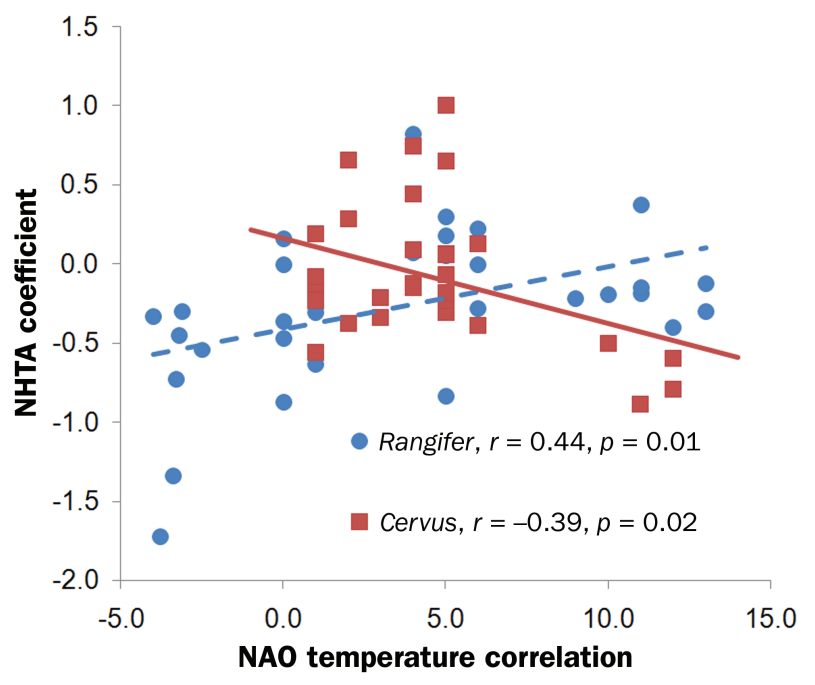

Figure 3. Correlation between population growth rate for Cervus and Rangifer populations and Northern Hemisphere temperature anomalies versus the strength of the local correlation between surface temperature and the North Atlantic Oscillation (NAO) from figure 3. The stronger the NAO-temperature correlation, the more local temperatures are affected by the NAO. This figure shows opposing relationships for Rangifer and Cervus, suggesting that the two genera will generally be affected in opposite directions by future warming.

Vucetich and Peterson 2004) illustrates an important example of nonstationary effects of climate change on population dynamics and, perhaps more interestingly, the role of species interactions in buffering a population from climatic fluctuations. In this example, an outbreak of canine parvovirus represented a pulse perturbation that altered the dynamics of the community and the role of large-scale climate in those dynamics (Wilmers et al. 2006). Before the outbreak, moose dynamics on the island were governed mainly by wolf predation and self-limitation, with a very minor, statistically insignificant climate influence (figure 4). After wolf densities were reduced dramatically by canine parvovirus, however, moose dynamics became strongly limited by the NAO.

Of course, this example does not illustrate patterns of distribution-wide dynamics - we mention it only because of the clarity with which it illustrates important features of population response to climate change that are likely to be important in distribution-wide variation in population dynamics. First, it corroborates predictions by Schmitz and colleagues (2003) arising from simulation modeling of moose response to future climate change across North America by demonstrating that species interactions may influence population response to climate. Second, it illustrates that predation may buffer populations from climate change (Wilmers et al. 2007). Third, it shows that climatic influences on population dynamics may not be stationary through time; that is, their importance may vary with the addition or removal of the limiting influences of species at adjacent trophic levels (Forchhammer and Asferg 2000).

\section{Advantages and limitations of time series analysis}

The approach we have described is traditional time series analysis (Royama 1992, Bjørnstad et al. 1995, Turchin 2003) of the relationships between population growth rate and climate and density for each population throughout a species' distribution. Using this approach, statistical coefficients quantifying the strengths of the influences of climate and density dependence on the dynamics of individual populations (equation 2) can be spatially examined for correlations with largescale spatial variation in climatic conditions, relations between climate systems and local weather, latitudinal gradients in primary productivity, or spatial variation in land-use patterns or other anthropogenic forces. This basic approach was used in the cuckoo (figure 1) and Cervus/Rangifer (figure 2) examples discussed above.

Traditional approaches to analyzing population dynamics through time-series analysis present both advantages and disadvantages compared with bioclimatic envelope modeling. First, time-series analysis can be used to decompose the contributions of intrinsic versus extrinsic processes to observed dynamics. Conventionally, this decomposition is based on inferences drawn from the autoregressive structure of timeseries data at a single trophic level. For instance, delayed autoregressive dynamics imply lagged life history effects on dynamics or interactions with species at adjacent trophic levels (Royama 1992, Stenseth et al. 1998a, 1998b, 1999), or both. Whether the processes underlying lagged dynamics relate to demography or species interactions is difficult to determine in the absence of age-structure data or overlapping time series at adjacent trophic levels. However, in a twospecies system, lagged autoregressive dynamics strongly imply demographic processes, whereas simple dynamics in a multitrophic-level system imply a lack of complex regulation due to interactions between demography and species interactions. In cases in which data at adjacent trophic levels are available, inferences about species interactions in dynamics at a single trophic level have been supported by analyses incorporating data on multiple species (Forchhammer and Asferg 2000, Bjørnstad and Grenfell 2001, Post and Forchhammer 2001, Schmidt et al. 2008). Additionally, experimental manipulation of predator-prey dynamics, combined with analyses of long-term data on prey abundance, confirms the role of species interactions in generating delayed dynamics in density time series (Bjørnstad et al. 2001).

A second advantage of time-series analysis in a globalpopulation dynamics framework is its ability to identify variation throughout species' distributions in the strengths of intrinsic versus extrinsic influences on population dynamics. For instance, Case and Taper (2000) emphasized that the importance of biological and abiotic influences on dynamics should not be expected to be constant throughout the distribution of a given species, and that spatial variation in the strengths of these processes explains the distribution of species 
and variation in their abundance throughout their distributions. Time-series analysis at the scale of entire species' distributions is ideally suited to identifying the limiting influences of both types of factors and distribution-wide variation in their importance.

The major drawback of time-series analyses is the additional data required. Compared with bioclimatic envelope modeling, which requires merely location data, acquiring time-series data requires long-term counts or indices of a species $(>25$ years, ideally) across a wide portion of the geographic range of a species. Critics may point out that these additional data requirements make the idea of global population dynamics problematic, but numerous recent studies (reviewed above) show that more and more, the availability of longterm and large-scale time series will enable these approaches. The Global Population Dynamics Database (NERC CPB 1999), for example, has more than 2000 published time series from more than 700 species and locations (Fagan et al. 2001, Boyce et al. 2006, Morris et al. 2008), and longterm, high-quality bird survey data from North America and data from global plant phenological monitoring and population counts are available; thus, this approach is the next logical step in expanding ecologists' ability to predict the effects of climate change on species.

A second major drawback in traditional time-series analyses concerns data quality, as many published data sets of species counts have unknown bias and various methods of accounting for detectability (or even none at all). Fortunately, recent advances in state-space modeling approaches provide tractable solutions to dealing with messy data in time-series analysis (De Valpine and Hastings 2002, Clark and Bjørnstad 2004). By treating time-series analysis as a two-step process to identify the most likely underlying error structure that generated the counts, and then separating out the likely true observations from the error model, ecologists are now starting to explore the factors that generate variation in timeseries analyses linked to climate change (Forchhammer and Post 2004, Wang et al. 2006).

\section{Choice of climate driver}

One of the first steps in scaling up to global population dynamics to understand the impacts of climate change is the choice of a global climatic variable, and an approach to determining which are the most important climatic drivers. The past decade has seen an explosion in the use of the NAO large-scale climatic index (Forchhammer and Post 2004, Hurrell 1995, Walther et al. 2002), especially in western Europe and eastern North America, to explain terrestrial and marine ecosystem dynamics. In the Pacific region, climate will generally be dominated by the ENSO or the Pacific Decadal Oscillation (Trenberth and Hurrell 1994), and in the Arctic, by the Arctic Oscillation (Thompson and Wallace 1998).
The choice of which regional climatic index to use is an important question, however, and especially for continentalscale analyses, as species may transcend the spatial domain of a particular climatic index. For example, Canada lynx ( $\operatorname{Lynx}$ $\operatorname{lyn} x$ ) show different population dynamical responses to winter snowfall in eastern versus western North America, mediated by the different climatic effects of the NAO and the ENSO, respectively (Stenseth et al. 1999). Stenseth and colleagues (1999) showed that lynx population dynamics vary across subcontinental ecological regions that match regions defined by the relationship between the global indices and local weather, suggesting a strong link between local weatherclimate interactions and population dynamics. The approach of Stenseth and colleagues (1999) is one among many for determining which climatic variables to apply, including model selection (Sandvik et al. 2008), correlation analyses with local weather variables (Grotan et al. 2008), or ordination methods that integrate different indices into similar orthogonal axes (Wang et al. 2006). Most important, within a climatic region there will be climate-change hot spots where the global climate index has a stronger influence on local weather variables such as precipitation and temperature (e.g., figure 2). The degree to which these in turn influence population dynamics can be determined with a cross-correlation analysis between climate and population dynamics using time series analyses.

\section{Future steps for understanding impacts of climate on global population dynamics}

Although the use of bioclimatic envelope models has been fruitful for many years, we still need supplemental approaches that can identify distribution-scale variation in intrinsic versus extrinsic processes in species' response to climate change (Schmitz et al. 2003), and the future for more detailed analy- 
ses of population dynamics looks promising. The rise of widely available, long-term population data online (such as the Global Population Dynamics Database) will facilitate analyses such as those promoted here. Moreover, to date, most global analyses have been conducted on only one species. The availability of extensive data sets with overlapping species suggests that ecologists will develop approaches for understanding community responses to climate change, a development that could not be more timely.

\section{Acknowledgments}

This article resulted from a workshop organized by E. P. at the Aarhus University, Denmark, supported by a grant to E. P. from the National Science Foundation (NSF). We thank the participants of that workshop for stimulating and inspiring discussions: Peter Aastrup, Mads C. Forchhammer, Ditte Hendrichsen, Toke T. Høye, Jacob Nabe-Nielsen, Niels Martin Schmidt, Chris Topping, and Mary Wisz. Comments by three anonymous referees are gratefully acknowledged. A. D. A. was supported by a graduate fellowship from Pennsylvania State University, and J. B. by the David H. Smith Conservation Research Fellowship. C. C. W. was supported by the NSF, and M. H. was supported by the University of Montana and the Canadian Association of Petroleum Producers.

\section{References cited}

Anders AD, Post E. 2006. Distribution-wide effects of climate on population densities of a declining migratory landbird. Journal of Animal Ecology 75: 221-227.

Araujo MB, Luoto M. 2007. The importance of biotic interactions for modelling species distributions under climate change. Global Ecology and Biogeography 16: 743-753.

Bjørnstad ON, Grenfell BT. 2001. Noisy clockwork: Time series analysis of population fluctuations in animals. Science 293: 638-643.

Bjørnstad ON, Falck W, Stenseth NC. 1995. Geographic gradient in small rodent density fluctuations: A statistical modeling approach. Proceedings of the Royal Society B 262: 127-133.

Bjørnstad ON, Sait SM, Stenseth NC, Thompson DJ, Begon M. 2001. The impact of specialized enemies on the dimensionality of host dynamics. Nature 409: 1001-1006.

Boyce MS, Haridas CV, Lee CT. 2006. Demography in an increasingly variable world. Trends in Ecology and Evolution 21: 141-148.

Case TJ, Taper ML. 2000. Interspecific competition, environmental gradients, gene flow, and the coevolution of species' borders. American Naturalist 155: 583-605.

Clark JS, Bjørnstad ON. 2004. Population time series: Process variability, observation errors, missing values, lags, and hidden states. Ecology 85: 3140-3150.

Clutton-Brock TH, Coulson T. 2002. Comparative ungulate dynamics: The devil is in the detail. Philosophical Transactions of the Royal Society B 357: 1285-1298.

De Valpine P, Hastings A. 2002. Fitting population models incorporating process noise and observation error. Ecological Monographs 72: 57-76.

Ellis AM, Post E. 2004. Population response to climate change: Linear vs. non-linear modeling approaches. BMC Ecology 4: 2.

Fagan WF, Meir E, Prendergast J, Folarin A, Karieva P. 2001. Characterizing population vulnerability for 758 species. Ecology Letters 4: 132-138.

Forcada J, Trathan PN, Reid K, Murphy EJ, Croxall JP. 2006. Contrasting population changes in sympatric penguin species in association with climate warming. Global Change Biology 12: 411-423.
Forchhammer MC, Asferg T. 2000. Invading parasites cause a structural shift in red fox dynamics. Proceedings of the Royal Society B 267: 779-786.

Forchhammer MC, Post E. 2004. Using large-scale climate indices in climate change ecology studies. Population Ecology 46: 1-12.

Forchhammer MC, Stenseth NC, Post E, Langvatn R. 1998. Population dynamics of Norwegian red deer: Density-dependence and climatic variation. Proceedings of the Royal Society B 265: 341-350.

Forchhammer MC, Post E, Stenseth NC, Boertmann DM. 2002. Long-term responses in Arctic ungulate dynamics to variation in climate and trophic processes. Population Ecology 44: 113-120.

Framstad E, Stenseth NC, Bjørnstad ON, Falck W. 1997. Limit cycles in Norwegian lemmings: Tensions between phase-dependence and densitydependence. Proceedings of the Royal Society B 264: 31-38.

Gompertz B. 1825. On the nature and function expressive of the law of human mortality, and on a new mode of determining the value of life contingencies. Philosophical Transactions of the Royal Society B 115: 513-585.

Grayson DK, Delpech F. 2005. Pleistocene reindeer and global warming. Conservation Biology 19: 557-562.

Grenfell BT, Wilson K, Finkenstädt B, Coulson TN, Murray S, Albon SD, Pemberton JM, Clutton-Brock TH, Crawley MJ. 1998. Noise and determinism in synchronized sheep dynamics. Nature 394: 674-677.

Grotan V, Saether BE, Filli F, Engen S. 2008. Effects of climate on population fluctuations of ibex. Global Change Biology 14: 218-228.

Hebblewhite M. 2005. Predation by wolves interacts with the North Pacific Oscillation (NPO) on a western North American elk population. Journal of Animal Ecology 74: 226-233.

Heikkinen RK, Luoto M, Virkkala R, Pearson RG, Korber JH. 2007. Biotic interactions improve prediction of boreal bird distributions at macroscales. Global Ecology and Biogeography 16: 754-763.

Hijmans RJ, Graham CH. 2006. The ability of climate envelope models to predict the effect of climate change on species distributions. Global Change Biology 12: 2272-2281.

Hurrell JW. 1995. Decadal trends in the North Atlantic Oscillation: Regional temperatures and precipitation. Science 269: 676-679.

Jedrzejewska B, Jedrzejewski W, Bunevich AN, Milkowski L, Krasinski ZA. 1997. Factors shaping population densities and increase rates of ungulates in Bialowieza Primeval Forest (Poland and Belarus) in the 19th and 20th centuries. Acta Theriologica 42: 399-451.

MacArthur RH. 1972. Geographical Ecology: Patterns in the Distribution of Species. Harper and Row.

Morris WF, et al. 2008. Longevity can buffer plant and animal populations against changing climatic variability. Ecology 89: 19-25.

[NERC CPB] National Environmental Research Council Centre for Population Biology. 1999. The Global Population Dynamics Database. (6 April 2009; www.sw.ic.ac.uk/cpb/cpb/gpdd.html)

Nikol'skii AA, Likhatskii YP. 2002. The effect of the wolf on the competition between ungulates in the Voronezh Biosphere Reserve. Doklady Biological Sciences 387: 520-522.

Parmesan C, Yohe G. 2003. A globally coherent fingerprint of climate change impacts across natural systems. Nature 421: 37-42.

Pearson RG, Dawson TP. 2003. Predicting the impacts of climate change on the distribution of species: Are bioclimate envelope models useful? Global Ecology and Biogeography 12: 361-371.

Peterson AT, Ortega-Huerta MA, Bartley J, Sánchez-Cordero V, Soberón J, Buddemeier RH, Stockwell DRB. 2002. Future projections for Mexican faunas under global climate change scenarios. Nature 416: 626-629.

Peterson AT, Mártinez-Meyer E, González-Salazar C, Hall PW. 2004. Modeled climate change effects on distributions of Canadian butterfly species. Canadian Journal of Zoology 82: 851-858.

Peterson RO, Thomas NJ, Thurber JM, Vucetich JA, Waite TA. 1998. Population limitation and the wolves of Isle Royale. Journal of Mammalogy 79: 828-841.

Post E. 2005. Large-scale spatial gradients in herbivore population dynamics. Ecology 86: 2320-2328. 
Post E, Forchhammer MC. 2001. Pervasive influence of large-scale climate in the dynamics of a terrestrial vertebrate community. BMC Ecology 5: 1 .

2006. Spatially synchronous population dynamics: An indicator of Pleistocene faunal response to large-scale environmental change in the Holocene. Quaternary International 151: 99-105.

Post E, Stenseth NC. 1999. Climatic variability, plant phenology, and northern ungulates. Ecology 80: 1322-1339.

Post E, Stenseth NC, Peterson RO, Vucetich JA, Ellis AM. 2002. Phase dependence and population cycles in a large-mammal predator-prey system. Ecology 83: 2997-3002.

Royama T. 1992. Analytical Population Dynamics. Chapman Hall.

Sakamoto Y, Ishiguro M, Kitagawa G. 1986. Akaike Information Criterion Statistics. Springer.

Sandvik H, Coulson T, Saether BE. 2008. A latitudinal gradient in climate effects on seabird demography: Results from interspecific analyses. Global Change Biology 14: 703-713.

Schmidt NM, Berg TB, Forchhammer MC, Hendrichsen DK, Kyhn LA, Meltofte H, Høye TT. 2008. Vertebrate predator-prey interactions in a seasonal environment. Pages 345-370 in Meltofte H, Christensen TR, Elberling B, Forchhammer MC, Rasch M, eds. Advances in Ecological Research, vol. 40. Elsevier.

Schmitz OJ, Post E, Burns CE, Johnston KM. 2003. Ecosystem responses to global climate change: Moving beyond color mapping. BioScience 53: 1199-1205.

Stenseth NC, Bjørnstad ON, Falck W. 1996a. Is spacing behaviour coupled with predation causing the microtine density cycle? A synthesis of current process-oriented and pattern-oriented studies. Proceedings of the Royal Society B 263: 1423-1435.

Stenseth NC, Bjørnstad ON, Saitoh T. 1996b. A gradient from stable to cyclic populations of Clethrionomys rufocanus in Hokkaido, Japan. Proceedings of the Royal Society B 263: 1117-1126.

Stenseth NC, Chan KS, Framstad E, Tong H. 1998a. Phase- and densitydependent population dynamics in Norwegian lemmings: Interaction between deterministic and stochastic processes. Proceedings of the Royal Society B 265: 1957-1968.

Stenseth NC, Falck W, Chan KS, Bjørnstad ON, O’Donoghue M, Tong H, Boonstra R, Boutin S, Krebs CJ, Yoccoz NG. 1998b. From patterns to processes: Phase and density dependencies in the Canadian lynx cycle. Proceedings of the National Academy of Sciences 95: 15430-15435.

Stenseth NC, et al. 1999. Common dynamic structure of Canada lynx populations within three climatic regions. Science 285: 1071-1073.

Thomas CD, et al. 2004. Extinction risk from climate change. Nature 427: 145-148.

Thompson DWJ, Wallace JM. 1998. The Arctic Oscillation signature in the wintertime geopotential height and temperature fields. Geophysical Research Letters 25: 1297-1300.
Tong H. 1990. Non-linear Time Series: A Dynamical System Approach. Oxford University Press.

Trenberth KE, Hurrell JW. 1994. Decadal atmosphere-ocean variations in the Pacific. Climate Dynamics 9: 303-319.

Turchin P. 2003. Complex Population Dynamics: A Theoretical/Empirical Synthesis. Princeton University Press.

Tyler NJC, Forchhammer MC, Øritsland NA. 2008. Nonlinear effects of climate and density in the dynamics of a fluctuating population of reindeer. Ecology 89: 1675-1686.

Vucetich JA, Peterson RO. 2004. The influence of top-down, bottom-up and abiotic factors on the moose (Alces alces) population of Isle Royale. Proceedings of the Royal Society B 271: 183-189.

Vucetich JA, Smith DW, Stahler DR. 2005. Influence of harvest, climate and wolf predation on Yellowstone elk, 1961-2004. Oikos 111: 259-270.

Walther GR, Post E, Convey P, Menzel A, Parmesan C, Beebee TJC, Fromentin JM, Hoegh-Guldberg O, Bairlein F. 2002. Ecological responses to recent climate change. Nature 416: 389-395.

Wang GM, Hobbs NT, Boone RB, Illius AW, Gordon IJ, Gross JE, Hamlin KL. 2006. Spatial and temporal variability modify density dependence in populations of large herbivores. Ecology 87: 95-102.

Wilmers CC, Post E, Peterson RO, Vucetich JA. 2006. Predator disease out-break modulates top-down, bottom-up and climatic effects on herbivore population dynamics. Ecology Letters 9: 383-389.

Wilmers CC, Post E, Hastings A. 2007. The anatomy of predator-prey dynamics in a changing climate. Journal of Animal Ecology 76: 1037-1044.

Eric Post (e-mail: esp10@psu.edu) is an associate professor of biology at Pennsylvania State University in University Park and an honorary professor in the Department of Arctic Environment, Aarhus University, in Roskilde, Denmark. Jedediah Brodie is a Smith Conservation postdoctoral researcher in the Smith Conservation Fellows program at Pennsylvania State University and the Wildlife Conservation Society in Gardiner, Montana. Mark Hebblewhite is an assistant professor in the Wildlife Biology Program at the University of Montana in Missoula. Angela D. Anders completed her PhD program at Pennsylvania State University, where she conducted this research, and is now a senior data analyst for Clancy Environmental Consultants and NOAA in Honolulu. Julie A. K. Maier is a research associate in the Department of Biology and Wildlife at the University of Alaska Fairbanks. Christopher C. Wilmers is an assistant professor in the Environmental Studies Department at the University of California, Santa Cruz. 